\title{
Ein Mikro-Verfahren zur Eisen- und Kupferbestimmung mittels Durchflußanalyse bei linearisierter Extinktionsmessung
}

\author{
Von H. HrRSCH \\ Aus dem Zentrallabor (Chefarzt: Dr. W. Fritzscbe) des Stadtkrankenbauses Frankfurt/Main-Höcbst
}

Technische Assistenz: H. Schenkel, I. Unger und D. Prcinic

(Eingegangen am 4. Juli/4. September 1973)

Aus Bauteilen der sog. I. Autoanalyzer-Generation und einem Eppendorf-Photomcter mit Schreiber wurde eine Continuous-flow-Konfiguration zusammengestellt, in dex nacheinander, unter Verwendung des identischen Schlauchsatzes, Serum-Eisen und -Kupfer analysiert werden. Durch eine lineare Konzentration-Extinktionsbeziehung vereinfacht sich die Standardisierung auf das Schätzen einer Geraden durch die Standardpeaks. Bei einem minimalen Verbrauch an Untersuchungsmaterial und einer Frequenz von 40 Proben/h ist die Verschleppung beim Kupfer immer, beim Eisen bis auf wenige Fälle vernachlässigbar. Dic erreichte Reproduzierbarkeit ist befriedigend. Hämolyse und der Verzicht auf spezielle eisenfreie Gefäße hatten keinen nachweisbaren Einfluß auf die Ergebnisse der Eisenanalyse.

\section{A micro metbod for the determination of iron and copper with the aid of continuous flow analysis with linearlized measurements of extinction}

A continuous flow procedure for the successive determination of serum iron and serum copper, using the same tubing, was devised with the aid of a first generation autoanalyzer and an Eppendorf photometer with a chart recorder. There is a linear relationship between concentration and extinction so that standardization is simplified to the measurements of a slope through the standard peak. With the minimal consumption of test material and a frequency of 40 samples $/ \mathrm{h}$, the carry over is always negligible for copper and, with a few exceptions, for iron. The reproducibility is satisfactory. Haemolysis and the use of special iron-frec vessels had no detectable effect on the results from the analysis of iron.

Die hohe Zuwachstate der in unserem Labor durchgeführten Eisen- und Kupferbestimmungen im Serum stellte uns vor die Aufgabe, diese zu mechanisieren. Zur Verfügung stand eine Autoanalyzer-Konfiguration der sog. I. Generation. Methodenblätter des Geräteherstellers für Eisen- und Kupfer-Bestimmungen existieren für den Autoanalyzer I nicht, jedoch wurden besonders für das Eisen immer wieder neue Arbeitsvorschriften von verschiedenen Autoren (z. B. 1-11) veröffentlicht - bereits Hinweise auf die Problematik der Analyse dieser beiden Spurenelemente auf diesem Gerät.

In jüngstẹr Zeit haben KatTermanN und KöHring (10) sowie BERNEGGER et al. (11) Autoanalyzer-I-Fließschemata für das Serum-Eisen und -Kupfer vorgestellt. KATTERMANN und KöHRING analysieren parallel in einem Zweikanalverfahren, wobei als Komplexbildner für das Eisen das Bathophenanthrolin und das Oxalyldihydrazid für das Kupfer verwendet werden. Erhebliche Nachteile dieses Verfahrens sind der große apparative Aufwand und der Serumbedarf von etwa $3 \mathrm{ml}$. BernegGer et al. bestimmen Eisen und Kupfer konsekutiv auf einem Einkanalgerät mit einer Frequenz von 30 Proben/h unter Verwendung eines weitgehend identischen Fließschemas. Die Chemie entspricht dabei im Prinzip der bei KatTERManN und Köhring beschriebenen, jedoch wird als Chelatbildner für das Eisen das „HLR 7777“", ein Benzodiazepin, verwendet. Die Extinktionsmessung exfolgt in einer $50 \mathrm{~mm}$ -
Durchflußküvette, wodurch der Einsatz von $0,4 \mathrm{ml}$ Serum pro Analyse genügt.

Es war erstrebenswert bzw. notwendig, das letztere, uns im Prinzip zusagende Verfahren in einigen Punkten zu modifizieren:

1. Der auf dem Markt nicht mehr erhältliche Farbstoff „HLR 7777“ mußte durch einen geeigneten anderen ersetzt werden. Naheliegend war die Verwendung von Bathophenanthrolin $(6,9,12)$. Da wir jedoch aus bisher noch nicht geklärten Gründen gelegentlich (entgegen 12,13) auch im sauren $\mathrm{pH}$-Bereich eine Interferenz des Kupfers mit der Eisen-Bathophenanthrolinreaktion beobachtet haben (14), entschieden wir uns für das Ferrozin $(1,9,15,16)$, bei dem sich die Interferenz des Kupfers durch dessen Bindung an Neocuptoin abschwächen läßt (16). Als weiteren Vorteil besitzt das Ferrozin gegenüber dem Bathophenanthrolin einen um etwa 20\% höheren Extinktionskoeffizienten (16).

2. Die notwendigen Investitionen für den Kauf von Filtern und die Umrüstung auf eine $50 \mathrm{~mm}$-Küvette erschienen für das als überholt zu bezeichnende Kolorimeter I als unvertretbar hoch. Wir ersetzten deshalb das Kolorimeter durch ein Spektrallinien-Photometer mit einer $2 \mathrm{~cm}$-Durchflußküvette. Durch die Messung der Extinktion bei monochromatischem Licht sollte außerdem eine für die Praxis ausreichend lineare Konzentration-Extinktionsabhängigkeit erreicht werden. 
3. Das Fließschema sollte zur Vereinfachung der Bedienung für beide Bestimmungen völlig vereinheitlicht werden.

4. Die Analysenfrequenz von 30 Proben/h ist bei größeren Serien sehr langsam und sollte deshalb erhöht werden.

5. Da unser Laboratorium eine Kinderklinik mit zu versorgen hat, in der die Gewinnung ausreichender Mengen Venenblut oft problematisch ist, war es wünschenswert, die Probenmenge weiter $\mathrm{zu}$ verringern.

Folgende Charakteristika sollte das zu erarbeitende Fließschema außerdem aufweisen: eine vernachlässigbare Verschleppung und eine Reproduzierbarkeit, die diejenige der bisher angewendeten manuellen Verfahren (im Jahresmittel 1972 je etwa 5\%) erreicht.

\section{Methodik}

Herstellung der Reagenzien

Für die Kupferanalyse:

a) 0,5 mol/1 Salzsäure: $60 \mathrm{ml} 8,2 \mathrm{~mol} / 1$ Salzsäure Suprapur (Merck Art. Nr. 318) mit bidest. Wasser auf 11 auffüllen und $0,5 \mathrm{ml}$ Brij-35 zusetzen.

b) Farbreagenz: $1 \mathrm{~g}$ Oxalsäuredihydrazid (Merck Art. Nr. 1842) in 11 bidest. Wasser auflösen. Von dieser Stammlösung werden

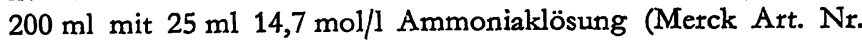
5432) und 7,5 $\mathrm{ml}$ Acetaldehyd (Merck Art. Nr. 4) versetzt. (Acetaldehyd nur kalt mit einem Meßzylinder dosieren wegen der Gefahr eines Siedeverzuges.) Im Kühlschrank eine Woche haltbar.

c) Physiologische $\mathrm{NaCl}$-Lösung: $11 \mathrm{mit}$ 0,5 ml Brij-35 versetzen.

\section{Fiir die Eisenanalyse:}

a) Ascorbinsäurelösung in $\mathrm{HCl}: 500 \mathrm{mg}$ Ascorbinsäure (Merck Art. Nr. 500078) in $0,5 \mathrm{~mol} / 1 \mathrm{HCl}$ (mit Brij-35 versetzt) lösen. Im Kühlschrank eine Woche haltbar.

b) Farbreagenz: $150 \mathrm{mg}$ Ferrozin (Hach) und $150 \mathrm{mg}$ Neocuproin (Merck Art. Nr. 2968) in einem $250 \mathrm{ml}$ Kolben mit $1 \mathrm{ml}$ $8,2 \mathrm{~mol} / 1 \mathrm{HCl}$ (s. o.) versetzen, etwas schwenken und bis zur Marke mit bidest. Wasser auffüllen. Bei $4^{\circ} \mathrm{C}$ unbeschränkt haltbar.

c) $1 \mathrm{~mol} / 1$ Acetatpufferlösung $\mathrm{pH}$ 4,65: $136 \mathrm{~g} \mathrm{Na}$-Acetat $\cdot 3 \mathrm{H}_{2} \mathrm{O}$ (Merck Art. Nr. 6267) in etwa $1500 \mathrm{ml}$ bidest. Wasser lösen, dann

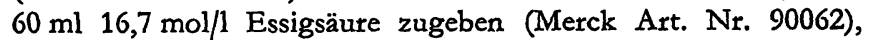
auf 21 auffüllen und $1 \mathrm{ml} \mathrm{Brij-35}$ zugeben.

Waschwasser: 21 bidest. Wasser mit $1 \mathrm{ml}$ Brij-35 versetzen.

Geräte

Probennehmer, Schlauchpumpe; Dialysator, Mischschlangen, TStücke und Debubbler entstammen der sog. I. AutoanalyzerGeneration. Das Wasserbad ist ein Standardgerät mit einem auf eine beliebige Temperatur einstellbaren Thermostaten. Das Photometer ist ein Modell der Fa. Eppendorf, wie auch der Kompensationsschreiber 6511 als Registriereinheit, der über die Möglichkeit einer stufenweisen Skalenspreizung verfügt. Die $2 \mathrm{~cm}$-Durchflußküvette (innerer Durchmesser $3 \mathrm{~mm}$ ) wurde von der Fa. Hellma, Mühlheim, bezogen. Weitere Einzelheiten sind dem Fließschema (Abb. 1) zu entnehmen.

\section{Arbeitsweise}

Wir beginnen mit der Analyse des Kupfers und lassen die des Eisens folgen, da bei dieser Reihenfolge die Notwendigkeit einer $Z$ wischenspülung weitgehendst entfällt. Lediglich der Schlauch für das Farbreagenz wird kurz im Waschwasser abgespült, dann werden alle drei Reagenzienschläuche in die entsprechenden Vorratsgefäße für die Eisenanalyse gehängt. Die Einstellung einer stabilen Basislinie dauert jeweils etwa $10 \mathrm{~min}$. Jede AnalysenSerie beginnt mit 5 primären Standards von $8,96,17,9,26,9$, 35,8 und $44,8 \mu \mathrm{mol} / 1 \mathrm{Fe}$ bzw. $7,85,15,7,23,6,31,4$ und $39,3 \mu \mathrm{mol} / 1$ $\mathrm{Cu}$, zwei Gefäßen mit Wasser (wobei spätestens beim zweiten Wasser die Basislinie wieder erreicht werden muß) und einem Sekundär-Standard. Die nun folgenden Patientenseren werden nach jeweils 10 Proben durch zwei Gefäße mit Wasser zur Kontrolle der Basislinie und einem Sekundär-Standard unterbrochen.

\section{Ergebnisse und Diskussion}

\section{Analysenfrequenz und Verhältnis Probe/ Waschflüssigkeit}

In Vorversuchen, in denen die Analysenfrequenz und das Verhältnis Probe/Waschflüssigkeit variiert wurden, wurde orientierend die Verschleppung und die Präzision in der Serie beobachtet. Eine Analysenfrequenz von 40 Proben/h bei einem Proben/Waschwasserverhältnis von 1/2 versprach alle gestellten Anforderungen zu erfüllen. Eine Analysenfrequenz von 50 Proben ergab zwar ebenfalls brauchbare Resultate, jedoch unter Abnahme der Präzision. Wir analysieren deshalb bei 40 Proben/h. Alle folgend referierten Ergebnisse wurden unter diesen Bedingungen ermittelt.

Linearität der Beziehung zwischen Konzentration und Extinktion

Die Abhängigkeit der Peakhöhe als Analogon der Extinktion von der Konzentration ist in Abbildung 2 am Beispiel je einer Standardreihe für Eisen und Kupfer dargestellt. Die berechneten Ausgleichsgeraden rechtfertigen für die Praxis die Annahme einer direkten linearen Proportionalität zwischen Konzentration und Extinktion für die in Abbildung 2 dargestellten Kon-
Abb. 1

Fließschema

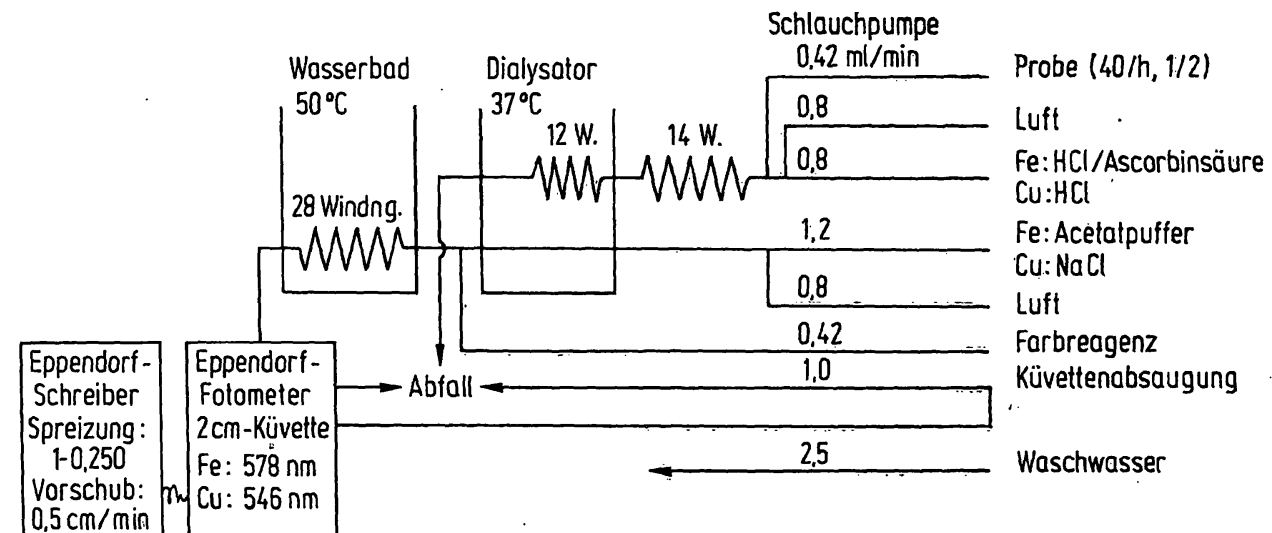




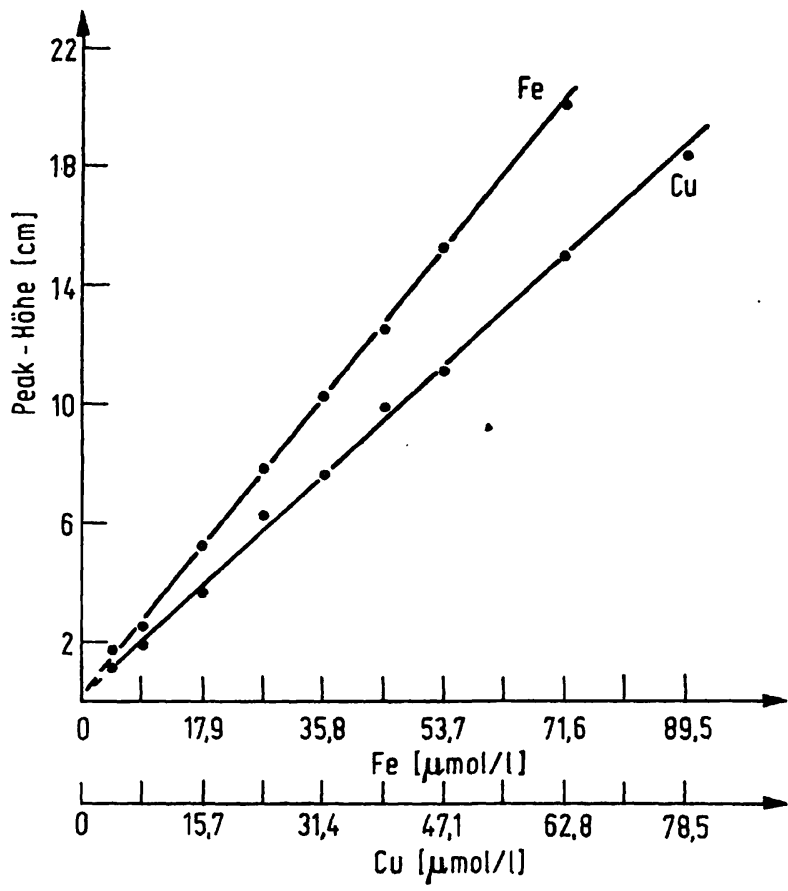

Abb. 2

Korrelation zwischen Konzentration und Peakhöhe bei je einer Reihe primärer Standards. Korrelationskoeffizienten und Regressionsgeraden: $\mathrm{Fe}: r=0,9996, y=0,273 x+0,22$; $\mathrm{Cu}: r=0,9988$, $\mathbf{y}=0,235 \mathbf{x}+0,22$
$0,273 x+1$

zentrationsbereiche. Bei der graphischen Resultatermittlung vereinfacht sich dadurch die Standardisierung auf das Schätzen einer Geraden, die mit Hilfe eines Lineals durch die Peaks der Standards gezogen wird. Mathematisch lassen sich die Analysenresultate nach Ausmessen der Peaks durch Vergleich mit einem Standardpeak, bzw. bei Vorhandensein eines programmierbaren Tischrechners durch Einsetzen in die Ausgleichsgerade schnell berechnen. Über das zuletzt genannte Verfahren wurden die Ergebnisse der vorliegenden Arbeit ermittelt.
Präzision in der Serie

Zur Ermittlung der Präzision in der Serie wurden mehrere Poolseren verschiedener Konzentration je 15-fach in einer Serie analysiert. Die Ergebnisse gibt Tabelle 1 wieder.

\section{Reproduzierbarkeit}

Die Reproduzierbarkeit wurde einmal geschätzt aus einer Kurzzeitserie, in der 12 Misch- bzw. Richtigkeitskontrollseren an zehn verschiedenen Tagen innerhalb von drei Wochen analysiert wurden und zum anderen aus der täglichen statistischen Qualitätskontrolle mit einem Richtigkeitskontrollserum der Behringwerke (Charge 114 A). Die Ergebnisse der Kurzzeitserie zeigt Tabelle 1. Es fallen beim Eisen wie beim Kupfer $z$. T. stark differierende Variationskoeffizienten auf. $\mathrm{Da}$ jeder Schätzung jedoch nur zehn Einzelwerte zugrunde liegen, kann man daraus nicht auf eine unterschiedliche Qualität der Kontrollseren schließen. Eine Korrelation zwischen den Mittelwerten und den Variationskoeffizienten besteht nicht $(r=-0,207$ für $\mathrm{Fe}$ und $-0,037$ für $\mathrm{Cu}$ ). Es wurden deshalb aus den je 12 Variationskoeffizienten die Mittelwerte berechnet, die der wahren Reproduzierbarkeit dieser Kurzzeitserie nahe kommen dürften. Aus dem bei der täglichen statistischen Qualitätskontrolle angefallenen Datenmaterial der Monate März bis Juni 1973 wurde für das Eisen ein VK von $5,7 \%$ bei einem Mittelwert von $15,3 \mu \mathrm{mol} / \mathrm{l}$ und für das Kupfer ein VK von $4,5 \%$ bei einem Mittelwert von $19,8 \mu \mathrm{mol} / \mathrm{l}$ berechnet.

Die gering schlechtere Reproduzierbarkeit der Monate März bis Juni kann durch Einflußfaktoren, wie Personalwechsel, Inkonstanz der Reagenzien, Veränderungen am Fließsystem, z. B. Pumpenschlauchwechsel, erklärt werden, die in einer 4-Monatsperiode natürlich zahlreicher zum Tragen kommen als in drei Wochen. Die

Tab. 1

Präzision in der Serie und von Tag zu Tag

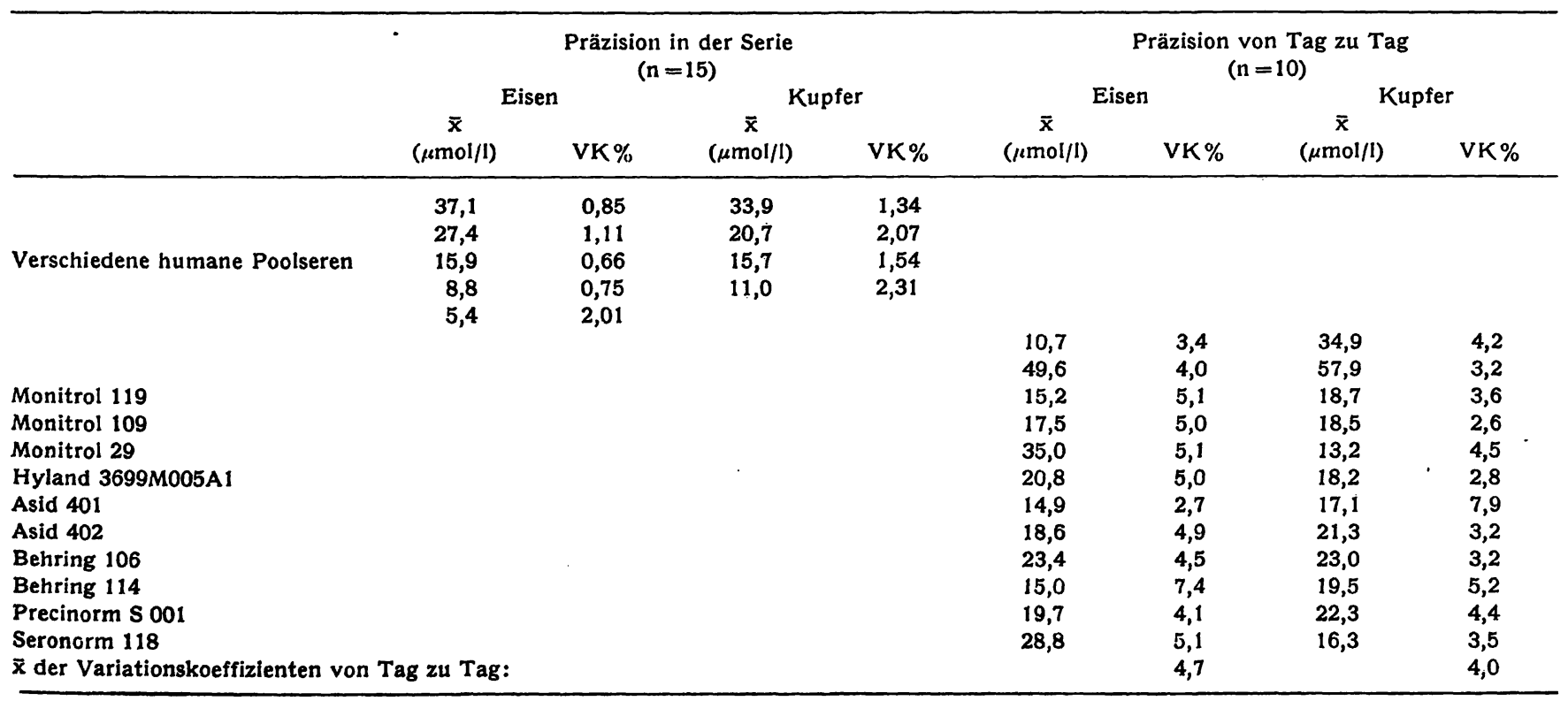


Reproduzierbarkeit ist übereinstimmend mit KATTERMANN und KöHRING und BERNEGGER et al. beim Eisen schlechter als beim Kupfer. Die ausgezeichneten Variationskoeffizienten von BERNEGGER et al: (für $\mathrm{Fe}$ etwa $3,9 \%$, für $\mathrm{Cu}$ etwa $1,7 \%$ ) werden bei unserem Verfahren zwar nicht erreicht, jedoch halten wir im Routinelaboratorium Variationskoeffizienten um $5 \%$ bei Parametern wie Eisen und Kupfer, die interindividuell und im Falle des Eisens auch intraindividuell so stark streuen, für ausreichend.

\section{Verschleppung}

Bei Serum-Eisen- und -Kupferanalysen ist in besonderem Maße auf die Verschleppung zu achten, da sehr niedrige Konzentrationen auf sehr hohe und umgekehrt folgen können. Von den zitierten Arbeiten (1-11) wird nur in (10) auf die Verschleppung eingegangen; Berechnungen in Form eines Verschleppungskoeffizienten wurden auch in (10) nicht angegeben. Wir haben die prozentualen Verschleppungskoeffizienten nach HJELM (17) berechnet, wobei wir von Poolseren mit Konzentrationen von 43,3 und 3,9 $\mu \mathrm{mol} / 1 \mathrm{Fe}$ und 41,8 und 3,9 (Poolserumverdünnung mit Albuminlösung) $\mu \mathrm{mol} / \mathrm{l} \mathrm{Cu}$ ausgingen. Die sehr günstigen $\mathrm{Er}-$ gebnisse zeigt Tabelle 2. Schließt man sich der Forderung von Haeckel und PORTH (18) an, daß der durch Verschleppungseffekte bedingte Fehler nicht größer als die zweifache Standardabweichung in der Serie sein darf, so kann man mit Hilfe der Verschleppungskoeffizienten für jeden Wert, für den die Standardabweichung in der Serie (Tab. 1) bekannt ist, Faktoren berechnen, um die die Konzentration der vorhergegangenen Probe größer bzw. kleiner sein darf, ohne daß die Verschleppung berücksichtigt werden muß, woraus sich verschleppungssichere Bereiche konstruieren lassen (zum Verfahren siehe bei (18)). Wenn, wie bei den Parametern Eisen und Kupfer, aus einem pathologischen Wert nur therapeutische Maßnahmen resultieren, die in ihrer Quantität nicht unmittelbar von der Höhe des pathologischen Wertes abhängen, kann man für die Klinikroutine über die oben gesetzte Grenze hinaus Verschleppungsfehler dann zulassen, wenn sie nicht zur Fehlzuteilung eines Einzelwertes bezüglich des Norm-Kollektives führen. Unter diesen Voraussetzungen muß hier beim Kupfer der Verschleppungsfehler überhaupt nicht, beim Eisen nur dann berücksichtigt werden, wenn auf einen Wert von $34,0 \mu \mathrm{mol} / 1$ und darüber ein Wert im Bereich zwischen 10,7 und $12,5 \mu \mathrm{mol} / 1$ folgt.

Tab. 2

Prozentuale Verschleppungskoeffizienten nach HJELM $\left(Q=q \times 100, Q_{1}=\right.$ Verschleppung von der niederen zur hohen, $\mathbf{Q}_{3}=$ Verschleppung von der hohen zur niederen Konzentration), Mittelwerte aus je 12 Einzelwerten

\begin{tabular}{lcc}
\hline & $Q_{1}$ & $Q_{2}$ \\
\hline Eisen & 1,69 & 0,69 \\
Kupfer & 0,98 & 0,83 \\
\hline
\end{tabular}

\section{Spezifität des Farbreagenzes}

Nach StookeY (15) wird die Eisen-Ferrozin-Reaktion nur durch Kupfer beeinflußt. Bei $562 \mathrm{~nm}$ fand er in einem $17,9 \mu \mathrm{mol} / \mathrm{l}$ Eisenstandard, dem $15,7 \mu \mathrm{mol} / 1$ Kupfer zugemischt waren $18,4 \mu \mathrm{mol} / 1$ (=103\%) Eisen, Charter (16) bei derselben Versuchsanordnung jedoch $20,0 \mu \mathrm{mol} / 1$ ( $=112 \%$ ). Letzterer konnte durch einen Zusatz von Neocuproin zum Ferrozinfarbreagenz die Interferenz des Kupfers auf 103,5\% abschwächen. Das Ergebnis eigener Untersuchungen (Pipettierschema: $0,5 \mathrm{ml}$ Acetatpuffer, $0,2 \mathrm{ml}$ Standard bzw. bidest. Wasser, 0,1 $\mathrm{ml}$ Farbreagenz; Reaktionszeit $10 \mathrm{~min}$ bei Raumtemperatur) gibt Tabelle 3 wieder, die zeigt, daß die geringste Kupferinterferenz bei $578 \mathrm{~nm}$ bei dem Farbreagenz mit Neocuproinzusatz beobachtet wird. Die unter den zuletzt genannten Bedingungen am Autoanalyzer gefundene Kupferinterferenz bestätigt den manuell ermittelten niedrigen Wert und ist deshalb vernachlässigbar. Die für die Farbentwicklung bei der Kupferanalyse notwendige Reaktionstemperatur von $50^{\circ} \mathrm{C}$ beeinflußt die Farbintensität des Eisen-Ferrozinkomplexes nicht.

Tab. 3

Einfluß von Kupfer auf die Eisen-Ferrozin-Reaktion. Die Tabelle zeigt die Menge Eisen in $\mu \mathrm{mol} / 1$ an, die ein Zusatz von $31,4 \mu \mathrm{mol} / 1 \mathrm{Cu}$ zu einem 17,9 $\mu \mathrm{mol} / 1$ Eisenstandard vortäuscht

\begin{tabular}{lll}
\hline \multicolumn{1}{c}{ Meßwellenlänge } & $546 \mathrm{~nm}$ & $578 \mathrm{~nm}$ \\
\hline Ferrozinreagenz ohne Neocuproin-Zusatz & 3,0 & 2,5 \\
Ferrożinreagenz mit Neocuproin-Zusatz & 0,79 & 0,32 \\
\hline
\end{tabular}

Richtigkeit

Zur Überprüfung der Richtigkeit wurden zunächst mehrere Richtigkeitskontrollseren analysiert, zur Eliminierung des Fehlers von Tag zu Tag an zehn verschiedenen Tagen. Die Mittelwerte wurden in je einem Korrelationsdiagramm in Abbildung 3 den Sollwerten gegenübergestellt. Abgesehen von den nicht berücksichtigten Punkten ist die Korrelation zwischen den gefundenen und den Sollwerten sehr gut. Die kleinen Ordinatenabschnitte sind mit der Annahme verträglich, daß die Geraden durch den Nullpunkt verlaufen. Die Eisenwerte liegen darin systematisch etwa $10 \%$ über den Sollwerten, die Kupferwerte dagegen etwa 10\% darunter. Aufstockungsversuche an zufällig ausgewählten Patientenseren ergaben in Richtung und Größenordnung dieselben Abweichungen wie in der obigen Versuchsanordnung (Tab. 4). Dies ist insofern bemerkenswert, als KATTERMANN und KöHrivig sowie BERNEGGER et al. trotz der prinzipiellen Gleichartigkeit der Analysensysteme ebenfalls unter. Verwendung wäßriger Standardlösungen solche Abweichungen nicht gefunden haben. KatTERMANN und KöHRiNG haben beim Vergleich mit allerdings nur einem kommerziellen Kontrollserum für beide Methoden eine Abweichung von nur $1-2 \%$ gefunden. BERNEGGER et al. berichten: „Bei beiden Verfahren ist die Wiederfindung in Ubereinstimmung zu den Literaturangaben voll befriedigend, 

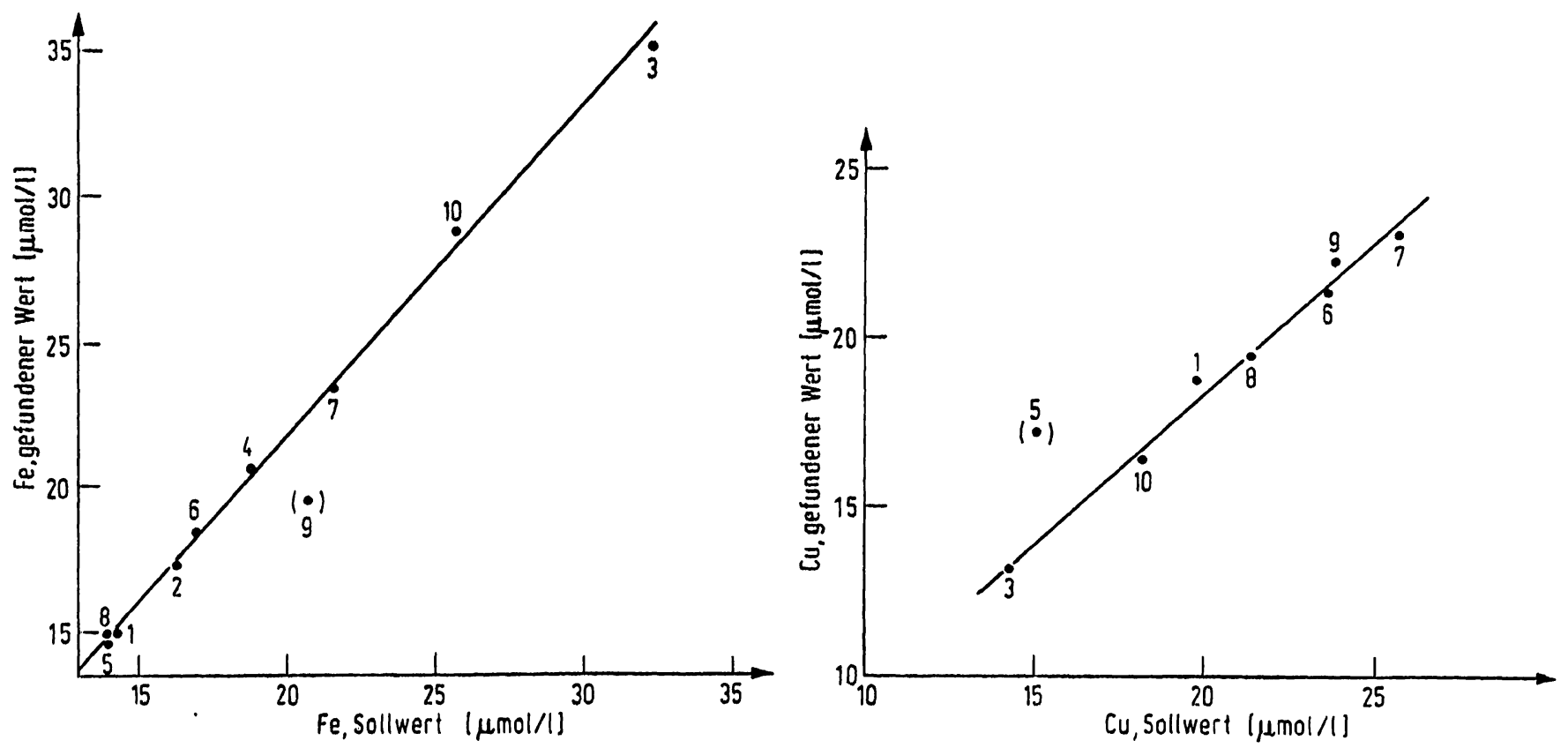

Abb. 3

Korrelation zwischen den Sollwerten verschiedener Richtigkeitskontrollseren und den gefundenen Werten. Die In Klammer gesetzten Plunkte

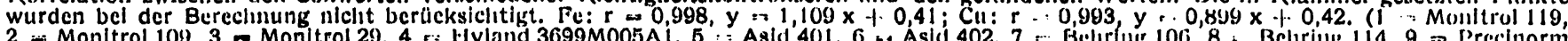

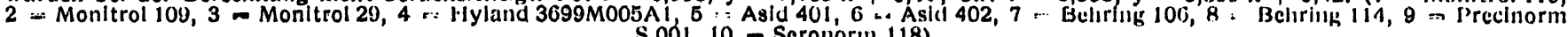
$S 001,10$ - Scronorm 118)

Talb. 4

Wiedurfindung unch Zusatz von $16,2 \mu \mathrm{mol} / 1 \mathrm{Fe}$ b\%w. $14,3 \mu \mathrm{mol} / \mathrm{l} \mathrm{Cu}$ zu verschledenen Humanscra

\begin{tabular}{|c|c|c|c|c|}
\hline & \multicolumn{2}{|c|}{ Eisell } & \multicolumn{2}{|c|}{ Kupfer } \\
\hline & $\mu \mathrm{mol} / \mathrm{l}$ & $\%$ & plnol/l & $\%$ \\
\hline Scrum 1 & 17,9 & 110,4 & 13,2 & 92,3 \\
\hline Scrum 2 & 18,1 & 111,7 & 13,4 & 93,7 \\
\hline Serum 3 & 17,5 & 108,0 & 13,4 & 93,7 \\
\hline Serunı 4 & 18,3 & 112,9 & 12,8 & 89,5 \\
\hline Serum 5 & 17,6 & 108,6 & 12,4 & 80,7 \\
\hline Serum 6 & 17,6 & 108,6 & 12,4 & 86,7 \\
\hline Seruin 7 & 17,9 & 110,4 & 12,7 & 88,8 \\
\hline Scruin 8 & 17,9 & 110,4 & 13,15 & y5, 1 \\
\hline Seruin 9 & 18,6 & 114,8 & 13,1 & 01,6 \\
\hline Serum 10 & 18,0 & 111,1 & 13,4 & 03,7 \\
\hline R & 17,9 & 110,7 & 13,0 & 91,2 \\
\hline
\end{tabular}

ihre Abweichungen vom Sollwert entsprechen der Streuung“. Ein Aufstockversuch mit wäßrigen Lösungen ergab eine Wiederfindung von $99,7 \%$ für das Eisen und 98,9\% für das Kupfer (Mittelwerte aus je 6 Einzelbestimmungen). Nach Mischen von Seren mit niedriger und hoher Fc- bzw. Cu-Konzentration in bestimmtem Verhältnis schwankte dic Wicderfindung nur wenig um $100 \%$ (Tab. 5). Scren verhalten sich demnach im System offensichtlich anders als wäßrige Lösungen. Als ideal muß deshalb cine Standardisicrung mittels Seren angestrelut werden. Die Ergebnisse der Korrelations- und Regressionsberechnung aus $\mathrm{Ab}$ bildung 3 rechtfertigen jedoch eine Korrektur der Resultate, für die wir uns - wie beschricben - als vorläufig cinfachste Lösung entschieden haben.

Hämolysc-Einfluß auf die Eisen-Bestimmung Zur Prüfung der Frage, in welchem Umfang aus Hämolyse stammendes Hämoglobincisen bei der vorliegenden Methode crfaßt wird, wurden Hämolysatc mit $\mathrm{Hb}$-Konzentrationen von $2,60,1,30,0,65$ und $0,33 \mathrm{~g} / \mathrm{l} \mathrm{Hb}$ hcrgestellt und je vicrfach analysiert. Bci $2,60 \mathrm{~g} / \mathrm{l} \mathrm{Hb}$ wurden $1,0 \mu \mathrm{mol} / 1 \mathrm{Fe}$, bei $1,30 \mathrm{~g} / \mathrm{l} \mathrm{Hb}$ wurden $0,5 \mu \mathrm{mol} / \mathrm{l} \mathrm{Fe}$ gefunden. Bei cincr Hb-Konzentration von $0,65 \mathrm{~g} / \mathrm{l}$ und darunter ist das Hämoglobineisen nicht mehr sicher nachweisbar. $\Lambda$ uch in einem Zumischversuch bei 12 verschiedenen Scren, denen \%u jc $1 \mathrm{ml}$ Serum 0,1 ml bidest. Wasser bəw. 0,1 $\mathrm{ml} \mathrm{Hämo-}$ globinlösung entsprcchend einer Endvcrdünnung von etwa $0,5 \mathrm{~g} / \mathrm{l} \mathrm{Hb}$ zugesetzt wurden, ergab sich im $\mathrm{t}-\mathrm{T}$ - $\mathrm{est}$

Tab. 5

Wlederfindung nach Mischen zweler Scren in bestlunitem Verhaltuis (Mitlelwerte aus je drel Bestimnumgen)

\begin{tabular}{|c|c|c|c|c|c|c|c|c|}
\hline \multicolumn{3}{|c|}{$\begin{array}{l}\text { Misclıverhıaltnls } \\
\text { Serumı A:Serıın B }\end{array}$} & $\frac{\begin{array}{c}\text { gefunde } \\
\text { amol/1 }\end{array}}{11,4}$ & $\begin{array}{c}\begin{array}{c}\text { Elsen } \\
\text { erwartet } \\
\mu \mathrm{mol} / 1\end{array} \\
-\end{array}$ & $\begin{array}{c}\begin{array}{c}\text { Wleclerflndung } \\
\%\end{array} \\
\end{array}$ & $\frac{\begin{array}{c}\text { sefindel } \\
\text { punol/1 }\end{array}}{10,5}$ & $\begin{array}{c}\begin{array}{c}\text { Kupfer } \\
\text { erwartet } \\
\text { amol/l }\end{array} \\
\end{array}$ & $\begin{array}{c}\begin{array}{c}\text { Wlederflindung } \\
\%\end{array} \\
-\end{array}$ \\
\hline 3 & : & 1 & 19,6 & 10,6 & 100,0 & 14,5 & 14,8 & 98,1 \\
\hline 2 & : & 1 & 24,5 & 22,4 & 00,6 & 16,2 & 10,2 & 100,3 \\
\hline 1 & : & 1 & 26,8 & 27,0 & 104,1 & 18,7 & 18,9 & 98,7 \\
\hline 1 & : & 2 & 33,7 & 33,3 & 08,8 & 21,0 & 21,8 & 100,5 \\
\hline 0 & : & 1 & 44,3 & - & - & 27,4 & - & - \\
\hline
\end{tabular}


für gepaarte Stichproben kein signifikanter Unterschied (p > 0,4). Da Hämoglobinkonzentrationen von über $0,65 \mathrm{~g} / \mathrm{l}$ im Serum kaum und über $1,25 \mathrm{~g} / 1$ nicht zu erwarten sind, braucht bei dieser Methode die Hämolyse nicht berücksichtigt werden.

\section{Zur Notwendigkeit der Verwendung sog. eisenfreier Gefäße}

Bei 40 Patienten wurde aus jeweils derselben Venenpunktion stammendes Blut bzw. Serum einmal nur mit „eisenfreien" Glas- und Plastikgefäßen in Berührung gebracht und zum anderen in Glasröhrchen, wie sie sich üblicherweise bei uns in Umlauf befinden, transportiert und aufbewahrt. Die Serumeisenwerte wurden ermittelt und einander im t-Test für gepaarte Stichproben gegenübergestellt. Mit einem $\mathrm{p}$-Wert von $>0,60$ ist damit zumindest für unsere Glaswaren ein Einfluß auf die Serumeisenwerte äußerst unwahrschein- lich. Wir verzichten deshalb für die beschriebene $\mathrm{Me}-$ thode auf die Verwendung sog. eisenfreier Röhrchen.

\section{Benötigte Serummenge}

Unseres Wissens ist bisher noch kein mechanisiertes Verfahren für die Eisen- und Kupferanalyse beschrieben worden, bei dem je Analyse nut $0,2 \mathrm{ml}$ Serum verbraucht werden. Zusammen mit einer entfallenden Notwendigkeit besonderer Vorsich'tsmaßnahmen beim Umgang mit dem Probenmaterial dürfte damit das Bereitstellen eines eigenen Röhrchen Blutes für die Eisen- und Kupferanalyse meistenteils überflüssig werden. Darauf, daß die geringen benötigten Serummengen besonders in der Pädiatrie Vorteile bringen, braucht nicht besonders hingewiesen werden.

\section{Danksagung}

Herrn Dr. R. Helger von der Fa. E. Merck, Darmstadt, danke ich für die freundliche Vermittlung des benötigten Ferrozins.

\section{Literatur}

1. Hünteler, J. L. A., van der Slik, W. \& Persijn, J.-P. (1972), Clin. Chim. Acta 37, 391-397. - 2. Fürhr, J. \& Stary, E. (1970), Ärztl. Lab. 16, 244-253. - 3. Leppla, W., Brokate, W. \& Keller, H. E. (1963), Internat. Techn. Sympos. Automat. Analyt. Chemie 225-229. - 4. Schmidt, R., Wers, W., KIINGMǗlLER, V. \& Staudinger, H. J. (1967), diese Z. 5, 304-309. 5. Young, D. S. \& Hicks, J. M. (1965), J. Clin. Pathol. 18, 98-102. - 6. ZAK, B. \& Epsten, E. (1965), Clin. Chem. 11, 641-644. - 7. Delcourt, R. (1964), Internat. Techn. Sympos. Automat. Analyt. Chemie 513-518. - 8. Summers, R. M., Meffert, R. B., jr. \& Littleton, H. R. (1964), Internat. Techn.
Sympos. Automat. Analyt. Chemie 459-463. - 9. YEE, H. Y. \& ZIN, A. (1971), Clin. Chem. 17, 950-953. - 10. KatTermanN, R. \& Köhring, B. (1971), diese Z. 9, 391-395. - 11. BernEGGer, A., KelleR, H. \& WeNGER, R. (1972), diese Z. 10, 359-362. - 12. SMITH, G. F., MCCuRdY, W. H., jt. \& Diemr, H. (1952), Analyst 77, 418-422. - 13. Lanpers, J. W. \& Z Z (1958), Amer. J. Clin. Pathol. 29, 590-592. - 14. HrrsCH, H., in Vorbereitung. - 15. Stookey, L. L. (1970), Anal. Chem. 42, 779-781. - 16. Carter, P. (1971), Anal. Biochem. 40, 450-458. 17. HJelM, M. (1968), Z. analyt. Chem. 243, 781-790. - 18. Haeckel, R. \& Porth, A. J. (1972), diese Z. 10, 91-94.
Dr. H. Hirsch Stadtkrankenhaus 623 Frankfurt-Höchst Gotenstr. 